\title{
Suitability of a Group Behavioural Therapy Module for Workplace Smoking Cessation Programs in Malaysia: a Pilot Study
}

\author{
Muhammad Faizal Maarof ${ }^{1}$, Adliah Mhd Ali' ${ }^{*}$, Noh Amit ${ }^{2}$, Mohd Makmor \\ Bakry $^{1}$, Nur Akmar Taha ${ }^{1}$
}

\begin{abstract}
In Malaysia, data on components suitability the established smoking cessation module is limited. This exploratory study aimed to evaluate the suitability of the components developed in the module for group behavioural therapy in workplace smoking cessation programs. Twenty staff were identified but only eight individuals were selected according to the study criteria during the recruitment period in May 2014. Focus group discussion was conducted to identify themes relevant to the behavioural issues among smokers. Thematic analysis yielded seven major themes which were reasons for regular smoking, reasons for quitting, comprehending smoking characteristics, quit attempt experiences, support and encouragement, learning new skills and behaviour, and preparing for lapse/relapse or difficult situations. As a result, the developed module was found to be relevant and suitable for use based on these themes.
\end{abstract}

Keywords: Group behavioural therapy - smoking cessation - workplace - qualitative study - Malaysia

Asian Pac J Cancer Prev, 17 (1), 207-214

\section{Introduction}

Smoking-related diseases have become the primary cause of mortality for the past three decades in developing countries including Malaysia (Lim et al., 2013). Consequently, financial cost has been spent every year to treat smoking-related diseases and the health care cost has been gradually increased (Syed Junid, 2007; Development and Planning Division, 2010) with the increment number of smokers. Even though the Ministry of Health (MOH) of Malaysia provides smoking cessation services through 294 quit smoking clinics (QSCs) (Development and Planning Division, 2010), the prevalence of smoking in Malaysia has increased by $1.6 \%$ between the year 2006 and 2011, regardless of the definitions used by the surveys (Third National Health and Morbidity Survey, 2006; Global Adult Tobacco Survey, 2011). Thus, the aim of $\mathrm{MOH}$ is to reduce the prevalence of current smokers into half by the year 2020 (Lim et al., 2013).

One of the potential causes of increasing number of smokers is failure in training adequate number of health care providers in Smoking Cessation Program (SCP) (Development and Planning Division, 2010; Lee et al., 2013). Regular training will strengthen health care providers with soft skills in addition to nonpharmacological approach such as behavioural support which is important since smoking is associated with nicotine addiction, physical and behavioural involvement (Maguire et al., 2001; Lee et al., 2011).

A study conducted among the smokers who sought SCP at eight QSC in Primary Health Centers in Malaysia concluded that there is a strong need to increase the participation rates from various groups of target population rather than waiting for smokers to attend the QSC (Wan Putih et al., 2008). Therefore, workplace smoking cessation program (WSCP) is an alternative option to promote the SCP in which large groups of people can be reached including young men and middle-aged smokers (Cahill et al., 2008; Yasin et al., 2011). The WSCP's intervention comprises of group therapy, individual counselling, self help materials, medications, incentives approach and social support (Cahill et al., 2008). Besides that, the WSCP may encourage a sustainable peer group support as an opportunity for smokers to learn behavioural change techniques, sharing their problems and experiences with other members of the group (Stead and Lancaster 2005). The effectiveness of WSCP has been evaluated and there is evidence that it may increase the worker's abstinence rates (Smedslund et al., 2004; Cahill et al., 2008).

There are several modules of SCP that have been used for the purpose of health promotion activities or research in Malaysia. The training module for healthy lifestyle campaign at workplace has been introduced by $\mathrm{MOH}$ in 
year 2004 which involved various parties such as smoker and non-smoker staffs, employers and management officers as the target groups (Health Education Division, 2004). It addresses the comprehension of quitting method, assertive skills, staying non-smoking status, smoke free environment and influencing smoking colleagues. To date, the data on the effectiveness of this campaign and continuation of using this module at workplace is limited.

In 2004, MOH and Malaysian Pharmaceutical Society in collaboration with other agencies has launched the Corporate Smoking Cessation (CSC) program following the establishment of pharmacist training course for Certified Smoking Cessation Service Provider (CSCSP) (Anon 2004). The aim of the program is to help workers to discontinue their smoking habit. To date, the data on the success of pharmacist training course for SCP and continuation of the CSC project is also limited. The CSCSP training module is not developed specifically for the group behavioural therapy (GBT) at workplace but rather as a guide for pharmacists to initiate their smoking cessation services.

Studies (SchrÖter et al., 2006; Pimple et al., 2012) showed that delivering intensive group behavioural interventions at workplace with different approaches such as standard behavioural approach, relapse prevention program and psychotherapy technique can be effective. Another WSCP was conducted among staffs in public universities in Klang Valley, Malaysia and it was found that the intervention of incorporating at least two sessions of cognitive behavioural therapy with the pharmacotherapy yielded about $22 \%$ of cessation rate within six-months (Yasin et al., 2011). The sessions consisted of coping strategies, risks and benefits of quitting, relapse prevention, stress reduction and weight control.

To the best of our knowledge, there is lack of study in Malaysia that evaluates the suitability of the components developed for group behavioural module in smoking cessation program. Therefore, this study aimed to identify themes relevant to the behavioural issues among smokers. These themes were used to evaluate the suitability of the module that was developed for group behavioural therapy in WSCP.

\section{Materials and Methods}

\section{Setting and Participants}

This study was conducted from May 2014 to August 2014 in Universiti Kebangsaan Malaysia (UKM), Kuala Lumpur Campus. Purposive sampling was conducted which included staffs who were regular smokers and at least in the contemplation stage of quitting smoking (i.e. interested in quitting in the next six months), based on the Transtheoretical Model (Prochaska and DiClemente, 1983; Fava et al., 1995; Norman et al., 1998; Velicer et al., 1999). Invitation was extended by distribution of flyers, invitation letters through the Head of Department (HOD) and by face to face approach. Participants were excluded if they had any cognitive, hearing or speech problem, or did not get permission from their HOD to join the program. Eligible participants were given a set of self-administration questionnaire regarding their smoking habits. They were then asked to provide their informed consent and were given the continuous training point and gift cards as a token of appreciation for their participation and time. Focus group discussions were conducted in the consultation room of Health Psychology Clinic, Faculty of Health Sciences, UKM. This study was approved by the Registrar of UKM and UKM Medical Centre Research Ethics Committee with reference number (UKM 1.5.3.5/ 244/ NF-017-14).

\section{Research team}

The research team in this study comprises of a pharmacist (MFM), 3 healthcare experts in the fields of clinical/ community pharmacy practice (AMA, MMB, NAT) and a psychologist (NA). There was no relationship between the research team-participants.

\section{Study Tools}

A set of questions was developed based on literature review (Lim et al., 2009; Rohani and Syed 2011; Michie et al., 2011) and SCP guidelines (Disease Control Division, 2003; McEwen et al., 2007; Fiore et al., 2008) for application in focus group discussion. Behavioural module was developed based on extensive literature review (Smedslund et al., 2004; Stead and Lancaster 2005; SchrÖter et al., 2006; Cahill et al., 2008; Michie et al., 2011), SCP guidelines search (Disease Control Division, 2003; Health Education Division, 2004; GCHP NHS; McEwen et al., 2007; Fiore et al., 2008; Michie et al., 2008; Zwar et al., 2011) and discussions among expert panelists. It covers the elements of psycho-educative, behavioural and physical change technique, cognitive therapy and also prevention of weight gain (Table 1).

\section{Data collection for focus group discussion}

The focus group discussions were conducted by MFM and NA in two groups for four sessions. Participants $(n=8)$ were divided into two groups ( $n=4$ per group). The dates of the session were determined by the researcher. Efforts were made to reschedule the participants for upcoming sessions. After completing eight interview sessions, the researchers reviewed the responses from the participants to identify the themes. Suitability of the module was assessed by two ways $(i)$ using a questionnaire with a Likert scale of $(1=$ not at all suitable to $10=$ extremely suitable $)$ based on participants' self- ratings of the module at the end of the session and ( $i$ i) ensuring the behavioural issues that were identified as themes were included in developed module.

\section{Analysis}

Participant's demographic and smoking-related data were obtained using a questionnaire attached to the patient information sheet. The focus group discussions were conducted in Malay language during all sessions. All discussions were audio recorded and fully transcribed verbatim with participants' permission by MFM after each session. The transcripts were then translated to English language by MFM. Two independent raters rechecked the translated transcripts against the original transcription by back-translating the transcripts. The accuracy of the 


\begin{tabular}{cl}
\hline Session & Components \\
\hline 1 & Goals- Group support, Group agreement, Information about cigarette smoking, Smoking pattern, Smoking motives, \\
& Pros \& cons smoking and quit smoking, Reasons for quitting smoking, Benefit of quitting, Stages of change \\
2 & Re-visit group agreement, Reviewing a smoking diary, Previous quit attempts, Quit action planning, Withdrawal \\
& Symptoms, Social Support \\
4 & Coping skills- physical and behavioural effects, Staying motivated, Managing weight control \\
\hline
\end{tabular}

Table 2. Themes Identified by the Smokers

\begin{tabular}{l} 
Components, themes and subthemes \\
\hline Preparation to quit \\
Reasons of continuing smoking \\
The advantages of smoking \\
The disadvantages of cessation \\
Love about cigarette \\
Identifying reasons for quitting \\
The expectations in study involvement \\
The disadvantages of smoking \\
The advantages of cessation \\
Comprehending smoking characteristics \\
Smoking habit \\
Smoking pattern \\
Smoking environment \\
Nicotine dependence \\
Quit attempts experiences \\
Presence of withdrawal symptoms \\
Smoking triggers \\
Quit challenges \\
Quitting \\
Support and encouragement \\
Intra-treatment social support \\
Extra-treatment social support \\
Learning new skills and behaviour \\
Coping with smoking triggers \\
Coping with withdrawal symptoms \\
Reward for not smoking \\
Staying quit \\
Be prepared for lapse/relapse or difficult situations \\
Reasons of previous relapse \\
\hline
\end{tabular}

transcripts was verified by the independent raters and later was returned to the participants for comment(s) and/ or correction(s).

Following verbatim transcription, the data were analysed with the assistance of qualitative analysis software i.e ATLAS .ti v7 (GmbH, Berlin, Germany). All transcripts were analysed by the research team using the thematic analysis (Braun and Clarke 2006) approach. Each transcript was repeatedly read to identify the common themes and significant points raised by the participants. The focus discussions were continued until theoretical saturation was reached when no new information was being formed by subsequent interviews (Bowen 2008). The analysis primarily drew on deductive thematic coding, established by the discussion guides, with secondary inductive coding that helped disclosing any emergent themes from the discussion transcripts (Pope et al., 2000). All authors discussed the themes to refine the analysis (Braun and Clarke 2006). The themes were then discussed with independent researchers to ensure their reliability and trustworthiness (Anderson 2010). This lead to the establishment of the final inclusive thematic map (Table 2), which addressed the common themes across all participants.

\section{Results}

\section{Participant characteristics}

A total of twenty smokers were enrolled over a period of two-weeks in May 2014. However, only eight qualified smokers were willing to participate in this program. Meanwhile, other participants refused to participate because they were not interested to join the program or too occupied with their job prospects. All of the participants were Malay males, aged between 25 to 40 years old and working as supporting staff in different departments. Out of eight participants, through their self-reporting, six persons smoked ten or more cigarettes per day, five persons were being in contemplation stage and three persons planned to quit within one month (preparation stage). They were well educated (five persons were college graduates or beyond, three persons were secondary level or below) and seven persons were married with at least one child. They had low nicotine dependency based on the heaviness of smoking index, with the mean score of 1.25.

Result showed that all participants completed more than three sessions with completion rate of $84 \%$. Reasons of absence included family issues and being occupied with their job.

\section{Suitability of the program}

All the participants rated the components in the module as very suitable to extremely suitable (i.e a 9 or 10 on the 10-point scale). Seven major themes were found to be relevant to behavioural issues as listed in Table 3 . The seven themes were divided into three components which are preparation to quit, quitting and staying quit as mentioned in Table 2.

\section{Themes Identified \\ Preparation to quit}

\section{Reasons of continuing smoking}

All of the participants explained clearly their reasons for smoking during the interviews. Common self-reported reasons for smoking included coping with stress, overcoming boredom, as an enjoyment, improving alertness, socialising and as an aid in concentration. The hardship of life also forced some to smoke regularly as a substitute to food.

\section{Identifying reasons for quitting}

Majority of the participants were able to identify their 
reasons for quitting. The main reason for quitting was their concern about personal and family's current and future health. These message aroused during the discussion regarding symptoms, physical findings and the presence of disease that may be worsened with smoking. Pressure from spouse or family, being a role model for their children, disliking the addiction, colleague's influences to quit and religious belief (Muslim) were motives for the smokers in deciding to stop. High cost of smoking did not make any impact to some participants since they could purchase the much cheaper illicit cigarettes. None of these participants felt the urgency to quit since lack of enforcement on the regulations and policies. The participants suggested that visual images illustrating health consequences of smoking could be used to persuade and increase awareness of the smokers to quit.

\section{Comprehending smoking characteristics}

All the participants discovered and understood their smoking characteristics by performing self-reported smoking diary and interviews. Participants did not notice their smoking pattern before, but began to realise after filling their smoking diaries for two weeks. They had different smoking habits and patterns when they were outdoors (i.e workplace) and indoors as they spent most of their time with smokers during working days. They respect their spouse or family by not smoking indoors and the quantity of sticks also was lower compared to being outside their home. Socialising with their peers may cause changes in their smoking patterns.

\section{Quit attempts experiences}

All the participants had quit attempt(s) experience during the past year with different methods of cessation in the minimum time of refraining from smoking. They had tried to quit without any assistance or had taken the opportunity to quit during the fasting month.

\section{Quitting}

Getting support and encouragement

\section{Table 3. Quotes}

\begin{tabular}{|c|c|}
\hline \multicolumn{2}{|l|}{ Preparation to quit } \\
\hline Themes & Quotes \\
\hline \multirow{2}{*}{$\begin{array}{l}\text { Reasons of } \\
\text { continuing smoking }\end{array}$} & $\begin{array}{l}\text { I do smoking to cope with finding ideas. When the target (business) is not achieved, then I have to } \\
\text { think of the solutions calmly, with the help of cigarettes. It is just to give relaxation, calmness and to let } \\
\text { them go (problems). This (smoking) is for small problems; as we took cigarettes, they will be 'settled'. } \\
\text { (Smoker } 05,32 \text { yrs) }\end{array}$ \\
\hline & $\begin{array}{l}\text {...I am afraid of getting the withdrawal symptoms again as it had happened in my previous quit } \\
\text { attempt...the quitting cost itself, because I had experienced it with my increased appetite. I would eat a } \\
\text { lot and want to try food that I had never eaten before. So, the cost was higher than cigarette. (Smoker } 06 \text {, } \\
30 \text { yrs) }\end{array}$ \\
\hline \multirow{2}{*}{$\begin{array}{l}\text { Identifying reasons } \\
\text { for quitting }\end{array}$} & $\begin{array}{l}\text {...I've one experience that really makes me think about quitting smoking. It happened when my toe } \\
\text { became black in color, and I thought it was gangrene but it was not...sometimes, when I look at my } \\
\text { physical appearance... looking at the lips. I feel unhappy when my lips seem to be darker than before. } \\
\text { At the same time, I also want to hide about it from my parents as they don't know that I am a smoker. } \\
\text { (Smoker } 01,28 \text { yrs) }\end{array}$ \\
\hline & $\begin{array}{l}\text { My wife always nags at me to stop smoking as I have promised her to do that before our marriage. My } \\
\text { intention to quit has become stronger. I hate the bitter taste of cigarette...Smoking is haram in Islam. } \\
\text { A lot of my friends have quit smoking successfully and they asked me to quit too. Personally, I feel } \\
\text { bad about the smoking habit. In addition, nobody is smoking in my father-in-law's family and I feel } \\
\text { embarrassed to them. (Smoker } 03,30 \text { yrs) }\end{array}$ \\
\hline \multirow{2}{*}{$\begin{array}{l}\text { Comprehending } \\
\text { smoking } \\
\text { characteristics }\end{array}$} & $\begin{array}{l}\text {...now, I just realised about my smoking pattern and I should focus on what I've got to do. I smoked } \\
\text { without thinking of the smoking pattern in the office. If I can focus (not to smoke) during office hour, } \\
\text { I should do the same thing when I'm outside especially with my friend(s). When I think and look back } \\
\text { (smoking dairy), why do I need cigarettes, I really don't need them and I don't enjoy them during } \\
\text { smoking. (Smoker 01, } 28 \text { yrs) }\end{array}$ \\
\hline & 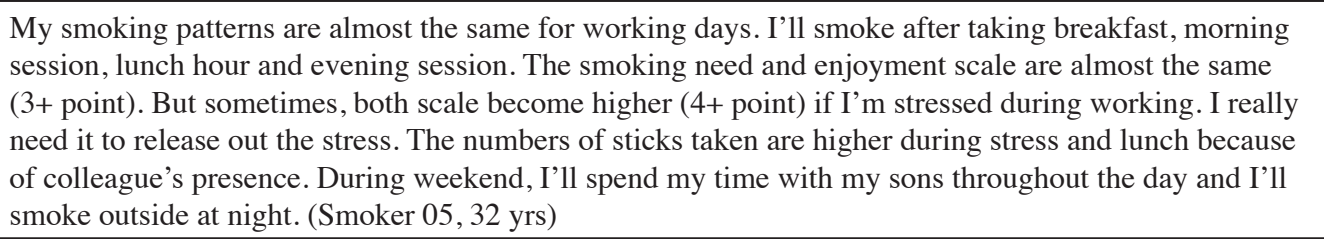 \\
\hline \multirow[b]{2}{*}{$\begin{array}{l}\text { Quit attempt } \\
\text { experiences }\end{array}$} & $\begin{array}{l}\text { I had experienced a quit attempt whereby I could only survive in quitting smoking for } 1 \text { week because } \\
\text { I had a fever and very bad coughing. So, I decided to smoke back and it seemed like curing my bad } \\
\text { situations. It was weird. (Smoker } 02,32 \text { yrs) }\end{array}$ \\
\hline & $\begin{array}{l}\text { I had an experience of not smoking during fasting month. Initially, I was not having bad fever or severe } \\
\text { coughing but it happened on the second week. Maybe, it's a detoxification process.... Sometimes, our } \\
\text { failure in quit attempt is caused by colleague's influences, who are smoking. If I've nothing to do in the } \\
\text { office, my colleague would ask me to accompany him for meals and we would enjoy smoking indirectly. } \\
\text { (Smoker } 07,40 \text { yrs) }\end{array}$ \\
\hline
\end{tabular}




\begin{tabular}{|c|c|}
\hline \multicolumn{2}{|c|}{ (Table 3. Quotes (Continue) } \\
\hline \multicolumn{2}{|l|}{ Quitting } \\
\hline Themes & Quotes \\
\hline \multirow[b]{2}{*}{$\begin{array}{l}\text { Support and } \\
\text { encouragement }\end{array}$} & $\begin{array}{l}\text { I have nobody to provide support in quitting process. Everyone wants to condemn me especially the } \\
\text { smokers. They get frustrated and tease me if they know that I want to quit. My colleague (woman) never } \\
\text { gives me any motivational support; even she is being cynical about it and ignores my intention to quit. } \\
\text { And I will never ask for my parents' support as they don't know that I am a smoker...If we need their } \\
\text { support (women), we have to tell them how they can help us. It takes time and we can't hope they can } \\
\text { understand well at the beginning. It is our role to tell them till they understand about it. (Smoker 01,28 } \\
\text { yrs) }\end{array}$ \\
\hline & $\begin{array}{l}\text { The smoking port is just next to our work station. Sometimes they (co-workers) will knock the door } \\
\text { and ask me to accompany them while smoking. When that happens, I'll smoke together with them... I } \\
\text { believe that my wife and sons could help me in quitting as I'll think of them whenever I want to smoke. } \\
\text { But, I'm not thinking of them when I'm smoking with my friends at workplace...From my point of view, } \\
\text { I could reduce the quantity of cigarettes or quit smoking by staying at a non-smoking zone such as the } \\
\text { airport area. I could refrain from smoking and was not thinking of that. Perhaps, it is due to the enforced } \\
\text { law. We can apply it at other non-smoking areas. It's all about our mindset. But, although our workplace } \\
\text { has been declared as a non-smoking area, we will sneak out to smoke at our closed, hidden smoking } \\
\text { port. (Smoker } 05,32 \text { yrs) }\end{array}$ \\
\hline \multirow{2}{*}{$\begin{array}{l}\text { Learn new skills } \\
\text { and behaviour }\end{array}$} & $\begin{array}{l}\text { I'll stop buying the cigarette and get closer to God...I'm controlling my mind. Think, feel and leave it. } \\
\text { For an example, when I feel the urge to smoke, I would go somewhere else or play with my baby. I try } \\
\text { not to smoke by distracting myself...I've tried drinking the sour flavoured water and smoking directly } \\
\text { but I couldn't continue and I ended up with throwing the cigarette away. It seems like the unpleasant } \\
\text { taste that usually we (smokers) feel during iftar in fasting month (smoke-free within } 8 \text { hours). (Smoker } \\
02,32 \text { yrs) }\end{array}$ \\
\hline & $\begin{array}{l}\text { I'll drink plenty of cold plain water as what I've done before. It works...Don't bring lighter or cigarette } \\
\text { everywhere. Although we can get it from our friends, it's just for a few times. We become embarrassed } \\
\text { to do it again... Stay away from our smoker friends if they are coming to tempt us to smoke...I believe } \\
\text { that I can quit smoking by keeping myself busy at workplace, so that I don't think about smoking...Apart } \\
\text { from that, we can apply the relaxation breathing technique. (Smoker } 05,32 \mathrm{yrs)}\end{array}$ \\
\hline \multicolumn{2}{|l|}{ Staying quit } \\
\hline Themes & Quotes \\
\hline \multirow{2}{*}{$\begin{array}{l}\text { Preparation for } \\
\text { relapse or difficult } \\
\text { situations }\end{array}$} & $\begin{array}{l}\text { I could reduce the sticks during working but I would be having a problem during hanging out with my } \\
\text { friends; I even didn't realise that I had smoked a lot. Thus, I'll let them know clearly that I already quit } \\
\text { smoking to get their support. (Smoker } 01,28 \text { yrs) }\end{array}$ \\
\hline & $\begin{array}{l}\text { I've tried to do fasting every Monday and Thursday to cope with the urge of smoking. It's very helpful... } \\
\text { When I'm at home, I try not to go out alone because automatically, I'll go to the shop to buy cigarette } \\
\text { as my first destination. It's not happening when I go out with my family. In the evening, I'll do cycling } \\
\text { around my house as a pastime. (Smoker } 07,40 \text { yrs) }\end{array}$ \\
\hline
\end{tabular}

Overall, this theme was well-received by the participants. Participants agreed that moral support from their spouse or family is needed in the quitting process. Unfortunately, they felt very difficult to obtain support from their spouse or co-workers, including their female colleague(s) due to strong peer-pressure from quitting and their efforts to quit were being ignored by those people. The spouses' confidence on their husbands' ability to quit was lacking because of previous false hopes. The participants also agreed that strict enforcement of smoking bans may help them to reduce daily consumption of cigarettes.

\section{Learning new skills and behaviour}

This theme seemed to be a very important component in GBT. Participants agreed that these topic need to be included in the module; coping with smoking triggers via managing stress and emotions, exercise, changing routines and distraction, relaxation breathing technique; coping with withdrawal symptoms, weight control method, physical activity; and reward for not smoking. Approach to quit smoking via fasting (for Muslims) could be an initial effort to reduce the quantity of cigarettes. Participant who had tried in their past for quit attempt, affirmed that fasting could help them to reduce the number of sticks or stop smoking.

\section{Staying quit \\ Be prepared for lapse/relapse or difficult situations}

The quit attempt(s)'s experiences and reason(s) for previous relapse were focused in the discussion to prevent future lapse/relapse. Smoking urges, nicotine withdrawal symptoms, stress and peer pressure became the main issues in this component.

\section{Discussion}

This pilot study was conducted to identify the themes relevant to the behavioural issues among Malaysian smokers. These identified themes were used to evaluate the suitability of the module that was developed for group behavioural therapy in smoking cessation program. We 
identified seven major themes that were found relevant to the behavioural issues which were already included in the developed module.

The themes including reasons of continuing smoking and identifying reasons for quitting may be able to help smokers to weigh the risks against the benefits of enduring smoking. These themes are included in the psycho-educative part of the developed module. Despite majority of Malaysian smokers regretted smoking and are aware of the bad health effects from smoking habit (The ITC Malaysia National Report, 2012), there is a probability that some of them underestimate the hazards. As recommended by Fiore et al., 2008 and Lim et al., 2009, the psycho-educative part in this behavioural module may assist in changing smoker's attitudes and beliefs about addiction and cessation. Indirectly, the in-depth discussion may enhance smoker's motivation and readiness to quit. Malaysian smokers in any stage of smoking behaviour change are recommended to discuss these important parts in the early stages of quitting especially the precontemplative smokers to assure they mobilised to a more advanced stage (Lim et al., 2013). Besides, providing information is recommended by most smoking cessation guidelines through 5A's and 5R's concept (Disease Control Division, 2003; Fiore et al., 2008; Zwar et al., 2011).

In order to understand about the psychological dependence and habit, the smokers need to understand their smoking characteristic through discussion and selfreported smoking diary. By recording their behaviour, it may help them to recognise their daily smoking pattern and triggers psychological or environmental factors. This may also be helpful for monitoring purposes and for smokers without any idea about their behavioural changes (Michie et al., 2008). The smokers' comprehension related to this issue may be able to facilitate the smokers to cope with smoking triggers and thus was included in the module.

Other identified theme was smoker experience in the course of quit attempt. Through this experience, smokers would identify their barriers during quitting as an effort to reduce the risk of smoking or relapse in their next quitting plan. This was also included in the module developed. Recognising the danger or difficult situations through quit attempt is suggested in the elements of practical tobacco counseling (Fiore et al., 2008). Thus, it is important for the smokers to know their reasons of relapse extensively, so it may provide valuable insights that will be proven useful in formulating further assistance and advice (Michie et al., 2008).

Other finding of our study was the support and encouragement in the quitting process as an important theme which has been included in the module. Smokers who are able to quit smoking have higher levels of appraisal support (Tsoh et al., 2011). It is important to facilitate the smokers with sources of support within their environment (Disease Control Division, 2003). Study showed that positive social supports generally are associated with a smoker's likelihood of successful quitting and negative social support such as nagging and teasing undermining the quit attempt (Rosky et al., 1996; Tsoh et al., 2011). Our finding is contradictory to another study (Yasin et al., 2011) in which psychosocial aspect do not predict cessation. Therefore, further exploratory studies are needed to investigate psychosocial aspect that predict cessation among Malaysian smokers. Apart from the regular provision of intra-treatment support, the spouse and peer pressure (extra-treatment social support) become critical to be discussed since smokers may feel lack of social support from them. Spouses may demonstrate less supportive behaviours with negativity as the smokers had previously given them false hopes. In addition, spouses may not be aware of their role in providing support such as assisting with the problems or providing relevant information to the smokers. The family-consultation approach suggested that social support is not only based on learning and implementing the support skills but requires an acknowledgement where others should be as part of the participants' behaviour change process rather than as providers of social support (Rohrbaugh et al., 2011).

Colleague(s) who are smokers may or may not be supportive to quitter(s), even though they have been informed at the initial phase of quit attempt. It is a challenge for the quitter (s) to quit when they are being surrounded with other smokers at workplace. This might be due to the mockeries from their co-workers; until at one stage, they decided not to quit. Their colleague(s) may also influence their quit attempt. If other smokers around them attempted to quit at the same time as they are, this may strengthen their aim of quitting. As suggested in other study in Malaysia (Fasoro et al., 2013), the top management may play an important role in supporting WSCP via stringent smoke-free regulations and enforcement especially at their illegal smoking zone at workplace. Another approach is to introduce reimbursement scheme in WSCP (Barker et al. 2002) for full coverage of pharmacotherapy and consultation cost. This will provide a great opportunity for the employees to quit successfully; however, this will depend on the budgets that the employers are willing to allocate.

Learning new skills and behaviour is about the cognitive-behavioural modification technique, specifically targeting an individual's behaviour. Planning and acting on the behaviour change may aid them to cope effectively with situations that could trigger craving or relapse (Fiore et al., 2008). Usually, the participants were able to decide which behavioural change technique they would prefer to incorporate and practise based on their lifestyle, habits on smoking urge and withdrawal symptoms (Michie et al., 2011). The easy practice of 4Ds (Delay, Deep breath, Drink, Distract) is useful to be implemented and is covered in the module developed (Zwar et al., 2011). The theme avoidance of potential relapse and risky situations may increase their awareness on behaviour change and abstinence. Being around smokers has been identified as the biggest challenge in maintaining abstinence. Hence, it is crucial to ensure that the smokers are aware on ongoing support after the treatment and the health care providers to keep delivering the relapse prevention intervention (Disease Control Division, 2003). The identified themes are covered completely by the module developed.

The suitability of the module also was established through positive ratings of the module by the participants. The participants agreed that those items in the module 
Suitability of a Group Behavioural Therapy Module for Workplace Smoking Cessation Programs in Malaysia: a Pilot Study

would help them to quit successfully as the program improved their beliefs and knowledge about smoking cessation. This is essential to ensure the module to be delivered is effective and successful. Previous studies showed that greater understanding of addiction and quit smoking treatments is associated with higher intentions and attempts to quit (Hammond et al., 2004; Lim et al., 2009; Rohani and Syed 2011; Asvat et al., 2014).

There are several limitations to our present study. The study was conducted among supporting staffs and predominantly involving Malay male subjects. It was unknown whether there were female staff(s) who smoke since none came forward to join this program. The findings of this study may not be generalised to other occupational level, gender and ethnicity. The use of purposive sampling method is subjected to bias. Thus, the results were limited to smokers who intended to quit, and this sampling method may not capture smokers with pre-contemplation stage.

This study provides information that could lead to an effective intervention program emphasising important behavioural approach and knowledge acquisition. These findings suggested that all behavioural components developed were important and could be applied in delivering group behavioural therapy.

\section{Acknowledgements}

The research was supported by Universiti Kebangsaan Malaysia Research Grant (UKM-Komuniti-2013-018). We would like to thank the participants and senior management of the faculty for the permission to conduct this study among their staffs. We are very grateful to the independent researchers for their help in the transcript analysis.

\section{References}

Anderson C (2010). Presenting and evaluating qualitative research. Am J Pharm Educ, 74, 141.

Anon (2004). 'Programme to help workers quit smoking'. Metro Star July 22, 2004. Malaysian Pharmaceutical Society. Web. December 20, 2013.

Barker D, Bentz CJ, Bjornson W, et al (2002). Reimbursement for smoking cessation therapy: A healthcare practitioner's guide. https:// www2.aap.org/ richmondcenter/pdfs/ PACTReimbursementforSmokingCessation.pdf.

Bowen GA (2008). Naturalistic inquiry and the saturation concept: a research note. Qualitative Res, 8, 137-152.

Braun V, Clarke V (2006). Using thematic analysis in Psychology. Qualitative Res Psychol, 3, 77-101.

Cahill K, Moher M, Lancaster T (2008). Workplace interventions for smoking cessation. Cochrane Database of Systematic Reviews, 4, 1-87.

Development, Planning Division, Ministry of Health, Malaysia (2010). Country Health Plan: $10^{\text {th }}$ Malaysia Plan 20112015. http:// www.moh.gov.my/images/gallery/Report/ Country_health.pdf.

Disease Control Division, Ministry of Health, Malaysia (2003). Clinical practice guidelines. treatment of tobacco smoking and dependence 2002. http://www.moh.gov.my/ attachments/3996.pdf. Accessed September 20, 2013.

Fasoro AA, Rampal L, Sherina MS, et al (2013). Prevalence of smoking and its associated factors among university staff.
Malaysian J Med Health Sci, 9, 45-51.

Fava JL, Velicer WF, Prochaska JO (1995). Applying the transtheoretical model to a representative sample of smokers. Addict Behav, 20, 189-203.

Fiore MC, Bailey WC, Cohen SJ, et al (2008). Treating tobacco use and dependence.clinical practice guideline. rockville, md: u.s. department of health and human services. public health service. http://www.ahrq.gov/professionals/cliniciansproviders/guidelines recommendations/tobacco/clinicians/ update/treating_tobacco_use08.pdf.

Glasgow Community Health Partnership (CHP) Northwest Sector. NHS Greater Glasgow and Clyde. Smoking cessation toolkit for young people: A toolkit for practitioners. http:// www.nhsggcsmokefree.org.uk/smokefree-services/youngpeople.html. Accessed November 23, 2013.

Hammond D, McDonald PW, Fong GT, et al (2004). Do smokers know how to quit? Knowledge and perceived effectiveness of cessation assistance as predictors of cessation behaviour. Addiction, 99, 1042- 1048.

Health Education Division, Ministry of Health, Malaysia (2004). Modul latihan Kempen Cara Hidup Sihat Setting Tempat Kerja.http://www.infosihat.gov.my/infosihat/kchs/ KCHS_2005/pdf/manualMesej/Modul\%20Latihan_BM.pdf.

Institute for Public Health, Ministry of Health, Malaysia (2008). National Health and Morbidity Survey Volume 17, Smoking. Kuala Lumpur.

Institute for Public Health, National Institute of Health, Ministry of Health, Malaysia (2012). Global Adult Tobacco Survey (GATS) Malaysia 2011. http://www.who.int/tobacco/ surveillance/ survey/gats/malaysia_country_report_2011. pdf.

Lee ML, Hassali MA, Shafie AA, et al (2011). Challenges of Pharmacist-Managed Smoking Cessation Services-A Viewpoint. Nicotine Tobacco Res, 13, 504-5.

Lee ML, Hassali MA, Shafie AA (2013). A qualitative exploration of the reasons for the discontinuation of smoking cessation treatment among Quit Smoking Clinics' defaulters and health care providers in Malaysia. Res Social Administrative Pharmacy, 9, 405-18.

Lim KH, Sumarni MG, Amal NM, et al (2009). Tobacco use, knowledge and attitude among Malaysians age 18 and above. Tropical Biomedicine, 26, 92-99.

Lim HK, S. Mohd Ghazali, Kee CC, et al (2013). Epidemiology of smoking among Malaysian adult males: prevalence and associated factors. BMC Public Health, 13, 8.

Lim KH, Normala I, Sumarni MG, et al (2013). Stages of smoking cessation among malaysian adults - findings from national health morbidity survey 2006. Asian Pac J Cancer Prev, 14, 805-10.

Maguire TA, McElnay JC, Drummond A (2001). A randomized controlled trial of a smoking cessation intervention based in community pharmacies. Addict, 96, 325-31.

McEwen A, Hajek P, McRobbie H, et al (2007). Manual of smoking cessation. a guide for counsellors and practitioners. Oxford. Wiley-Blackwell.

Michie S, Rumsey N, Fussell A, et al (2008). Improving health: changing behaviour. NHS health trainer handbook Manual. Department of Health Publications. Accessed December 24, 2014.

Michie S, Churchill S, West R (2011). Identifying evidencebased competences required to deliver behavioural support for smoking cessation. Ann Behav Med, 41, 59-70.

Norman GJ, Velicer WF, Fava JL, et al (1998). Dynamic typology clustering within the stages of change for smoking cessation. Addict Behav, 23, 139-53.

Pimple S, Pednekar M, Mazumdar P, et al (2012). Predictors of quitting tobacco - results of a worksite tobacco cessation 
service program among factory workers in mumbai, India. Asian Pac J Cancer Prev, 13, 533-8.

Pope C, Ziebland S, Mays N (2000). Qualitative research in health care: analysing qualitative data. $B M J, 320,114-6$.

Prochaska J, DiClemente C (1983). Stages and processes of selfchange of smoking: toward an integrative model of change. J Consult Clin Psychol, 51, 390-5.

Rohani I, Syed A (2011). Counselling intervention programme to improve knowledge and attitude towards smoking among adolescents in two districts in Selangor, Malaysia. Health Environment J, 2, 44-49.

Rohrbaugh MJ, Shoham V, Trost S, et al (2001). Couple dynamics of change-resistant smoking: toward a family consultation model. Fam Process, 40, 15-31.

Rosky J, Schmid LA, Lando HA (1996). Long-term associations of helpful and harmful spousal behaviors with smoking cessation. Addict Behavior, 21, 173-85.

SchrÖter M, Collins SE, Frittrang T, et al (2006). Randomized controlled trial of relapse prevention and a standard behavioral intervention with adult smokers. Addictive Behaviors, 31, 1259-64.

Smedslund G, Fisher KJ, Boles SM, et al (2004). The effectiveness of workplace smoking cessation programmes: a meta-analysis of recent studies. Tobacco Control, 13, 197-204.

Stead LF, Lancaster T (2005). Group behaviour therapy programmes for smoking cessation. Cochrane Database of Systematic Reviews. 2.

Syed Junid SMAJ (2007). Health care costs of smoking in Malaysia.http://www.seatca.org/dmdocuments/23_health_ care_costs_of_smoking_in_malaysia.pdf.

Tsoh JY, Tong EK, Gildengorin G, et al (2011). Individual and family factors associated with intention to quit among male Vietnamese American smokers: Implications for intervention development. Addictive Behaviors, 36, 294-301.

University of Waterloo, Waterloo, Ontario, Canada; Universiti Sains Malaysia, Pulau Pinang, Malaysia; and Ministry of Health, Putrajaya, Malaysia (2012). The international tobacco control malaysia national report. findings from Wave 1 to 4 Surveys (2005-2009).

Velicer W, Norman G, Fava J, et al (1999). Testing 40 predictions from the transtheoretical model. Addict Behav, 24, 455-69.

Wan Puteh SE, Abdul Aziz S, Syed Junid SMAJ, et al (2008). Patterns and predictors of smoking cessation among smokers attending smoking cessation clinincs in peninsular Malaysia. J Community Health, 14, 17-23.

Yasin SM, Masilamani R, Ming MF, et al (2011). Predictors of smoking cessation among staff in public universities in Klang Valley, Malaysia. Asian Pac J Cancer Prev, 12, 811-6.

Asvat Y, Cao D, Africk JJ, et al (2014). Feasibility and Effectiveness of a Community-Based Smoking Cessation Intervention in a Racially Diverse, Urban Smoker Cohort. Am J Public Health, 104, 620-627.

Zwar N, Richmond R, Borland R, et al (2011). Supporting smoking cessation: a guide for health professionals. Melbourne: The Royal Australian College of General Practitioners. http://www.racgp.org.au/. 